Article received on: 24th September 2015 Article accepted on: 15th October 2015

UDC: $781.1: 786.2$

781.68:786.2

COBISS.SR-ID 223350028

\author{
Ana Szilágyi* \\ Richard Wagner Conservatory, Vienna/Austria
}

\title{
A THEORY OF PIANO INTERPRETATION BASED ON CYBERNETICS
}

\begin{abstract}
Ana Pitiş and Ioana Minei discovered in the $70-80$ s, a complex theory of piano interpretation that gives another view in the art of piano playing. The two authors systematically research the original musical information coming from the composer. This information passes through more codes until it is perceived by the public: through the musical text (the score), through the musical images of the interpreter and through technical means. The merit of this theory lies in the fact that the authors point out the audio-mental operations that take place in the brain of the interpreter reading the score before playing. This interior hearing is based on musically characteristic operations, on sound ordering, respecting musical laws. The advantage of these operations is that the piano sound is no longer perceived as mechanical, but espressive, with meaning. In the opinion of the authors, the feedback of the cybernetics causes the sound perception of the public: the sound will be heard with qualities such as timbre, dynamics and expression.
\end{abstract}

Key Words: information, code, feedback, audio-mental operations, interior hearing

\section{Introduction}

The aim of this text is to describe and analyse the piano theory developed by the Romanian piano professors Ana Pitiş (1918-2014) and Ioana Minei (19312001). My study is based on their Treatise of Piano Art (Tratat de artă pianistică, București, Ed. Muzicală, 1982), which was simplified and published later under the title Theory of Piano Behaviour (Teoria comportamentului pianistic, Ed. Sf.

* Author contact information: ana.szilagyi@univie.ac.at 
Gheorghe-Vechi, 1997). The treatise, based on cybernetics, has not found a large audience among pianists and piano teachers because of its complexity, its interdisciplinarity and its scientific demonstration. Another difficulty for the readers is the fact that the material was not sufficiently systematized. It was more understood and appreciated by the pupils and students of Pitiş and Minei, including myself.

Ana Pitis and Ioana Minei tried to rationally explain the whole process of piano playing following the information from the score written by the composer and 'read' by the interpreter ${ }^{1}$, passing over the musical images of the latter and its materialization in piano sounds through technical means, until it reaches the public. In order to explain this process, the authors, besides music theory and cybernetics, resorted to linguistics, psychoacoustics and biomechanics, the purpose being to obtain quality piano playing, with respect for the text. However, the interpretation must mirror the era in which the interpreter lives and, at the same time, must distinguish him/her from others.

What is new in this theory is the interior hearing of the score by the interpreter reading the score, a quality that is well-developed by directors and, to a certain extent, by composers. The musical text has to be heard and processed according to musically characteristic laws and only then reproduced on the keys. These audio-mental operations are controlled and regulated by the feedback of cybernetics, a fact that I shall further explain. In the following pages, I have chosen to discuss some aspects of this piano theory, like the role of cybernetics in this theory, what the audio-mental operations are and the interdependence between them, the text, and the technical means. Finally, I would like to point out the advantages and disadvantages of this theory and to check its actuality and application.

\section{Cybernetics in piano theory. The role of hearing and listening}

Ana Pitis and Ioana Minei resorted to cybernetics in order to logically explain the act of piano interpretation. Cybernetics made it possible for people to analyse different systems and to understand how a system works, e.g. the rules that it is based on. These rules could later be formalized. Pitis and Minei tried to decompose the act of piano interpretation into multiple actions, i.e. into analysable operations. They considered piano playing to be a system similar to a mechanical, biological or social one and searched for the laws of the common function of these systems, and the piano system. The laws are based on information

\footnotetext{
${ }^{1}$ I have chosen to say "interpreter" and not "performer" because this theory is an interpretation theory of processing the data that are saved in the score.
} 
passing from the external part of a system to its internal part, or from one of its components to another. ${ }^{1}$ Any information needs a code in order to be sent and received. The code differs from one system to another, or from a component of the same system to another component. In the opinion of Pitis and Minei, the musical information passes through several codes until it arrives from the composer to the public: initially, the composer hears it and then he codifies it again in musical graphic signs (the score); the interpreter starts from the same code - the score - decoding it, but he has to change this code, processing the information taken from the score in his hearing and mind (audio-mental operations) before playing; finally, the interpreter has to change the code that is characteristic of the audio-mental operations in the forces, energies and movements characteristic of piano playing, that is to say, in piano technique, so that the information reaches the public. ${ }^{2}$ The initial information must reach the public undeformed, in spite of the change of codes. This occurs because between seeing the score and playing it, there is its interior hearing: the piano technique is subordinated to the hearing command. To represent this in simplified terms:

\section{not SEEING-PLAYING,}

\section{but SEEING-HEARING-PLAYING}

As a result of the interior hearing before playing, that is to say 'anticipative hearing', the piano sound appears to the public enriched, with qualities and differences in dynamics, timbre, slow tempo oscillations (microagogic) and expressivity, close to the initial information heard by the composer. All these qualities are partially or not noted in the score; only highness and duration are entirely noted.

The two authors explain this phenomenon with the feedback of cybernetics. The feedback follows the command and conversely sends the information from the output to the input of the system. Thus, the action can be controlled and a possible error can be corrected through a new command. ${ }^{3}$ In the case of the relation score-interpreter or interpreter-public, the feedback corrects the perception and the sound will be heard, respectively listened to, with all its qualities. Here, one should mention that human perception, especially auditory perception, is able to complete the absent elements in an auditory message if the last contains enough information and if the public receiving it has an auditory experience. ${ }^{4}$ In this way, the interpreter hears in advance (anticipative hearing) in his brain, the 'ideal sound', while the public can really hear the piano sound with all its quali-

\footnotetext{
1 Ana Pitis, Ioana Minei, Tratat de artă pianistică, București, Ed. Muzicală, 1982, 23.

2 Ibid., p. 25.

3 Ibid., p. 24.

4 Cf. ibid., p. 131.
} 
ties, even the piano sounds per se mechanically, i.e. without much possibility to create different dynamics, timbres or legato. The piano cannot produce the vibrato characteristic in the human voice, in other instruments, nor is it able to play in other tuning than in the tempered one. However, pianists and the auditorium are familiar with the human voice and wind/string instruments, as well as with different instrument combinations, at least in a certain musical language like classical music, whose code is known by the sender, as well as by the receiver(s). In this way, Pitis and Minei were convinced that the public could hear a piano sound with vibrato in other tuning systems than the tempered system. I want to add that this theory refers to traditional classical music, where the beauty and expression of the sounds are an important factor, and not to avant-garde experimental music, where the attention is focused on other aspects.

We have seen that the authors explained the importance of hearing in the piano interpretation, resorting to the feedback of the cybernetics. Besides anticipative hearing, there is 'control hearing' that obviously works on the feedback principle: the interpreter plays a note or a group of notes, he/she listens to what he/she has been playing, then decides what was not good in terms of the quality (for example, dynamic graduation or rhythmic grouping) and improves his/her playing with the proper technical means, which I shall further discuss.

The two authors mention that hearing and listening refer not only to the simple auditory sensation. They also involve other centres of the cortex, a fact that leads to associations. A simple auditory perception without associations means to know if sounds are high, loud, short, etc., but if an auditory stimulus has a certain significance for the listener, the auditory zone of the cortex works with other zones and has as a result a complex auditory analysis. ${ }^{5}$ The complex auditory analysis can be 'functional' and 'semantic'. The functional auditory analysis is strictly musical, the interpreter has to develop it, listening to a lot of music and learning the logical and functional relations (for instance, the function of a note within a phrase). This means to ordinate the material according to the musical logic. At a higher level is the semantic analysis, which moves beyond the music: "the capacity of semantic analysis, of the sound significance, is accompanied by the capacity of representing artistic images with rich senses, within whose process a great variety of architectonic centers of the cortex are stimulated, so that the music sounds are associated with visual images, with space, movement,

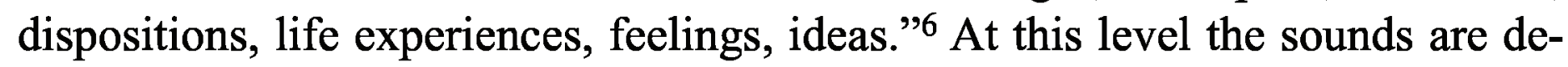
scribed as 'poetical, sharp, firm, warm, sad'.7

5 Cf. ibid., p. 49.

6 Ibid., p. 50.

7 Ibid., p. 50. 
Before finishing this chapter, one can conclude that in the vision of Pitis and Minei, music is a language, a mode of communication based on specific rules. The composer, through the interpreter, sends a message to the public. The message has to be coherent, intelligible and emotional. ${ }^{8}$ Therefore, the interpreter must respect the musical rules and develop his/her musical thinking. In the next chapter, I shall describe the elements that are characteristic of musical thinking.

\section{Musical thinking and image. Audio-mental operations - the role of dynamics, timbre and microagogics}

Audio-mental operations belong to musical thinking. In order to form musical thinking, musicians have to listen not only to piano music, but also to chamber and orchestral music and develop the skill to differentiate timbres and the finest dynamic graduations. Consequently, they have to think the sounds in relation one to another, in other words, to take account of the precedent and successive note, giving to every note the just intensity, colour, agogics and expression. This is intellectual work, where functional hearing plays an important role.

I would like briefly to discuss two audio-mental operations characteristic of musical thinking, such as the pitch and length parameter in connection with other parameters. Before, I wish to mention the close relation between dynamics and timbre, which for Pitis and Minei plays an important role in piano playing. These are just the elements that are not or only partially notated in the piano score. In their opinion, a little dynamic difference is perceived as a big timbre change. For example, an important sound in a phrase would be perceived as more brilliant if it were a little dynamically changed, i.e. played a little louder. In the same way, the impression of brilliance could be obtained there, even in the piano nuance. ${ }^{9}$ Parameters like pitch, harmony, counterpoint, and form are approached from the perspective of dynamics and timbre. Apart from dynamics and timbre, there is the microagogic element that refers to tiny accellerandi and ritardandi; accelerando often goes with a crescendo and intensification of the expression; ritardando, for instance, points out an important interval or stresses the end of a phrase.

\section{a) Pitch}

In order to get an expressive interval on the piano, the interpreter has to represent its sounds in his hearing with dynamics, timbre and microagogics (by a successive interval) and with dynamics and timbre (by a simultaneous interval). The result

\footnotetext{
${ }^{8}$ Cf. ibid., p. 29.

9 Ibid., p. 130.
} 
is a 'singing' sound, interval or chord. This quality of sound is obtained "taking into account its pitch in relation to the pitch of the precedent and the successive one - or overlapped - owing to certain dynamics and agogic differentiations." 10 This is a question of 'mental intonation'. "If these mental operations of intonation do not take place (when the pianist is wrong and believes that the interval on the piano is 'ready made'), the dynamic, timbral and agogic differences that take into account the expression of the interval, are not perceived." 11 In the opinion of Pitis and Minei, 'singing' the sounds of an interval would 'adjust' the tempered tuning that otherwise would be perceived as false.

The dynamic differences have to be done by chromatic issues, by notes which do not belong to the chord, by dissonances, by register change (the higher register a little louder than the middle or the grave one), the soprano in the melody or chord as well as the bass as fundamental in a chord, for stress a dominant or a modulation, etc.

\section{b) Length}

Within the rhythm, the authors studied the length and the accentuation rapports. Concerning the length, voice and other instruments can change the pitch (vibrato or portamento) or the dynamics (crescendo or decrescendo) during the length of the sound: "Although from the acoustic point of view the piano cannot offer varied, combined possibilities between, on the one hand, length and vibrato, and on the other, dynamic evolution, the pianist has to use a diversity of combinations in his representations, longer lengths in cantilena (especially in romantic repertoire), requiring an expressive 'enrichment' through the interior hearing of the sounds with vibrato ."12 As for the accentuation, the authors tried to unify two contrasting theories about metric and rhythm developed by Moritz Hauptmann, and respectively by Hugo Riemann. Hauptmann points out pulsation through accents, while Riemann finds this unmusical and proposes to mark the subdivisions of the measures through a little agogic separation of the motifs, which are dynamically stressed: crescendo with accelerando for off-beat motifs and decrescendo with ritardando for beat motifs. ${ }^{13}$ For Pitis and Minei, it is important to delimit the rhythmic formula, which contains an accent, but this must be expressive. ${ }^{14}$

\footnotetext{
10 Ibid., p. 54.

${ }^{11}$ Ibid., p. 55.

${ }^{12}$ Ibid., p. 61.

13 Ibid., pp. 62.

${ }^{14}$ Cf. ibid., p. 66.
} 
The audio-mental operations help the interpreter to structure the musical material in accordance with musical laws in order to send the auditorium a clear, expressive and attractive message. For this, the interpreter has to perform small, dynamic and rhythmic deviations from the text.

To confirm this, I quote Johann Sundberg, Anders Friberg and Lars Fryden, who later published the result of an acoustic experiment done in a laboratory in Stockholm: "Traditional music notation merely gives hints as to its acoustic realization; if the music is realized as nominally described by the score, a musically unacceptable performance emerges. This phenomenon demonstrates the musical relevance of the expressive deviations that musicians make from the nominal description represented by the music score." 15 They arrive at the same or similar conclusions concerning the musical perception, when trying to improve the performance of synthesizers controlled by a computer, which gives and modifies the rules in order to improve the performance. The score was written into a Mac minicomputer. ${ }^{16}$ The rules concerning the pitch, pitch interval, duration, plus information on chords and boundaries between phrases and sub phrases, generated expressive deviations from the score. ${ }^{17}$ The rules were given by music teachers, musicians and very good music students. Not only were piano pieces analysed, but also string quartet pieces where, for example, the frequency and the depth of vibrato play an important role. I recommend this article. This is not the place to discuss this experiment further, but I mentioned it because of its similarity with the piano theory of Pitis and Minei. It demonstrates that the theory discussed could also be applied on other instruments, certainly without losing sight of the specific characteristics of every instrument.

The musical image is on a higher level than the musical thinking. It includes the whole human personality, his culture, education, fantasy, sensitivity, life experiences, etc. It consists of a semantic process, the interpreter giving extra-musical meanings to the score. This is the aspect that reveals the difference between interpreters, the aspect that individualizes them. The semantic hearing, here, is active.

As for the semantic interpretation, the two authors believe that the pianist associates the musical field with the experiences of the extra-musical reality. One of them is the intonation in a language in which there are, like in music, accents, rhythm, durations, relations between durations, timbre and pitch chang-

15 Johan Sundberg, Anders Friberg, Lars Fryden, Common Secrets of Musicians and Listeners: An analysis-by-synthesis. Study of Musical Performance, in: Peter Howell, Robert West, Ian Cross (ed.), Representing Musical Structure, London, Academic Press, 1991, 161.

16 Ibid., 163.

17 Ibid., 164. 
es. ${ }^{18}$ Another extra-musical field is the space. In music, this means the interval change of place, the distance between the sounds of an interval, chord or register, which could suggest going far, vicinity, rise, descend, etc. Music can also suggest movement, for example, walking, marching, dancing, or movement in nature, with the sea or the wind as sources. The sense of time refers to mood changes, to time passing, waiting, timelessness or silence. The sense of colour, light, shadow associates the hearing center with the visual one. In my opinion, it is not possible to play Debussy well, without thinking of impressionist pictures. The sense of psychological contrasts, human characters or situations, associated with visual images, movements, and speech is important, too, for creating musical images. ${ }^{19}$

\section{Piano technique}

Compared with other instruments, Pitis and Minei consider that, where the piano is concerned, technical solutions are not the only ones that serve to obtain a certain sound quality or an expressive effect. ${ }^{20}$ The fingers (more exactly: the finger tips) have to properly respond to the auditory command and evaluate the energies that are to be sent to the keys. Then, they also have to send information to the arm regarding the favourite positions for obtaining these energies. The authors speak about kinetic energy, which has the formula $\mathrm{E}=1 / 2 \mathrm{~m} \mathrm{x} \mathrm{v}$, where the mass refers to the arm and the velocity to the fingers acting on the keys. ${ }^{21}$ The mass diversely contributes to increasing or decreasing the kinetic energy. "The pianist can get the finest differentiations of intensity through different combinations of the mass with the finger velocity that projects this mass on the keys." 22 The arm need not move vertically like the fingers, but only smoothly change the angles between it and the forearm. ${ }^{23}$ The last has a horizontal move. For a homogeneous sonority, one needs more arm mass and a reduction in the velocity of the finger; for a brilliant sonority, what means big intensity differentiations, one needs less participation of the arm and more degrees of finger velocity. ${ }^{24}$ The technical means depend on the auditory command: "The reaction to an auditory command offers a higher energy source than the energy obtained from voluntary

\footnotetext{
18 Ana Pitis, Ioana Minei, op. cit., pp. 124.

19 Ibid., p. 125-127.

20 Ana Pitis, Ioana Minei, Teoria comportamentului pianistic, Bucuresti, Ed. Sfantul GheorgheVechi, 1997, 100.

21 Ibid., p. 104.

22 Ibid., p. 107.

23 Ibid, p. 125, 115.

${ }^{24}$ Cf. ibid., p. 123.
} 
muscular efforts. It allows the almost unlimited graduation of the velocity and of the mass factor of the kinetic energy." 25 For the authors, the mental and psychic effort come first, while the hand and the arm have to be relaxed. For this, they hold that technical problems are removed by forming mental, specific skills. ${ }^{26}$

\section{Conclusions, critics, new ways}

In this study, I have tried to systematize the dense material of the Treatise of Piano Art written at the beginning of the 1980s by Ana Pitis and Ioana Minei, briefly describing the most important aspects of this piano interpretation theory. I discussed the role of hearing and listening that the two authors wanted to scientifically explain through the feedback of cybernetics, an achievement in that time. Cybernetics made it possible to explain many different phenomena, among them piano playing. The question could be asked: how would it be possible today, after the progress of science and technique, to justify this theory, based on hearing and listening? With or without a scientific demonstration, the theory is valuable concerning the audio-mental operations that have to take place in the brain of the interpreter (in order to achieve quality playing) before playing a piece, while reading the score. These operations are of a musical nature, in accordance with the laws that are specific to traditional classical music. The limitation of this theory is that it can be applied only to the classical traditional repertoire, from Baroque to the New Music of the $20^{\text {th }}$ century, excluding aleatoric, improvised and contemporary music without a score. An interesting aspect of this theory is the translation to the piano of the sound possibilities that are characteristic of other instruments or of voice, such as timbre, sound length, vibrato, legato, dynamics. In my opinion, it would also be possible to achieve an inverted transfer of the interior hearing used for piano playing in order to have a clear structure and a beautifully expressed sound on other instruments, even if these instruments possess greater technical possibilities for achieving diverse effects and avoiding mechanical sound. The subordination of technical movements to the auditory command is another achievement. To apply the kinetic formula to piano technique also involves a knowledge of physics and the anatomy, a fact that demonstrates the high culture and interdisciplinary view of the two authors.

In spite of criticism, it would be worthwhile to translate this treatise from Romanian into English for it to become better-known.

\footnotetext{
25 Ibid., p. 124.

26 Ibid., p. 128.
} 